\title{
DEVELOPMENT OF BIOTECHNOLOGY OF GETTING SELENIUM NANOSTRUCTURES WITH LACTOBACILLUS ACIDOPHILUS CULTURE
}

\author{
Leonid Kaprellyanz \\ Department of Biochemistry, Microbiology and Physiology of Nutrition \\ Odessa National Academy of Food Technologies \\ 112 Kanatna str., Odessa, Ukraine, 65039 \\ Natalia Zykova \\ Department of Biochemistry, Microbiology and Physiology of Nutrition \\ Odessa National Academy of Food Technologies \\ 112 Kanatna str., Odessa, Ukraine, 65039 \\ Arsen Petrosyants \\ Department of Biochemistry, Microbiology and Physiology of Nutrition \\ Odessa National Academy of Food Technologies \\ 112 Kanatna str., Odessa, Ukraine, 65039 \\ Alexander Zykov \\ Department of processes, equipment, energy management \\ Odessa National Academy of Food Technologies \\ 112 Kanatna str., Odessa, Ukraine, 65039
}

\begin{abstract}
Selenium nanostructures are characterized with high activity and antibacterial properties. Selenium nanoparticles, received by the biotechnological method using microorganisms are not toxic and free from admixtures of other toxic elements. For getting selenium nanostructures, there was set a problem of development of the biotransfrormation technology of inorganic selenium by the culture Lactobacillus acdophilus, strain 412/307 from the museum of the Department of Biochemistry, Microbiology and Physiology of Nutrition Odessa National Academy of Food Technologies (Ukraine). Selenium nanostructures are the side product in the process of selenocysteine formation. There was realized the study of the influence of the sodium selenite concentration on the growth speed and generation duration of lactobacteria on MRS medium for determining the main technological parameters. There was determined the quantitative content of accumulated selenium at different initial concentrations of sodium selenite in the medium. The important part of the elaborated technology is destruction of cellular walls of microorganisms for removal selenium nanoparticles. There was studied the influence of different physical-chemical factors of cells' destruction. There was offered to use the combined influence of saline acid, freezing and microwave field for destructing cellular walls of lactobacteria biomasses. There is presented the scheme of the technology of getting "Nanoselenium" and given physical-chemical parameters of the received product.
\end{abstract}

Keywords: sodium selenite, lactobacteria, nanostructures, optic density, specific speed of growth, generation duration.

\section{Introduction}

Selenium it is an essential microelement that plays an important role in physical processes in the human organism. It is included in the composition of many proteins and enzymes. Selenium can be in the inorganic form (selenates, selenites), in organic one (included in sulphur-containing acids) and as nanoparticles $\left(\mathrm{Se}^{0}\right)[1]$.

Complex preparations based on nanostructures of chemical elements are especially interesting. Literary data testify that the biological method of getting nanoparticles of elements can be realized using microorganisms, especially in the process of their cultivation in mediums with the content of inorganic forms of studied elements [2-4]. This method of nanoparticles creation has a 
series of advantages, namely the short time of cultivation of microorganisms and impossibility of forming side toxic products [5].

Selenium nanostructure is a side product of selenocysteine creation. Selenite-ions, arrived to a bacterial cell, create seleno-hydrogen with renewed glutathione. Selenium glutathione trisulphide is an intermediate product. Selenocysteine and $\mathrm{Se}^{0}$ are created of seleno-hydrogen with selenocysteinsynthase [6]. Selenium nanostructures are accumulated in the intracellular space, part of them comes to the cultivation medium through pores of the cellular wall. Selenium nanostructures have the spheric form, their sizes vary from 10 to $200 \mathrm{~nm}$ [7].

Nanostructures are more active than inorganic forms of selenium, they accumulate better in tissues, easily penetrate the cellular membrane and accumulate in the intracellular space [8,9]. Even at the very low selenium concentrations $(0,005-0,1 \%)$, its particles can adsorb antigens and antibodies on the surface. Nanostructures are characterized by antibacterial properties. It is known, that they are able to inhibit the growth of Staphylococcus aureus biofilms [10].

In this connection the important tasks in health-improving of the population are studies for developing new selenium-containing preparations. Obtained preparations must be characterized by the whole spectrum of selenium positive influence on the human organism, but as opposite to inorganic selenium forms, be safe for humans.

Thus, the aim of the work is the development of the biotechnology of getting the nanostructural selenium preparation with the culture Lactobacillus acidophilus 412/307.

\section{Materials and Methods}

The object of the researches was Lactobacillus acdophilus culture, strain 412/307 from the museum of the Department of Biochemistry, Microbiology and Physiology of Nutrition Odessa National Academy of Food Technologies (Ukraine). As a selenium source there was used sodium selenite $\mathrm{Na}_{2} \mathrm{SeO}_{3}$ (Chemel, SIE, LTD). MRS broth was chosen as a medium for lactobacteria cultivation.

Optic density was determined by taking suspension of the studied microorganisms at different cultivation stages. The change of optic density indices was determined using a photocolorimeter CPC-2-CCC 4.2 (AOMP, Russia) (a dish with the distance $1 \mathrm{~cm}^{3}$ ) (Fig. 1). According to obtained data, there were built the graphs in semi-logarithmic coordinates and the growth specific speed and generation duration were determined.

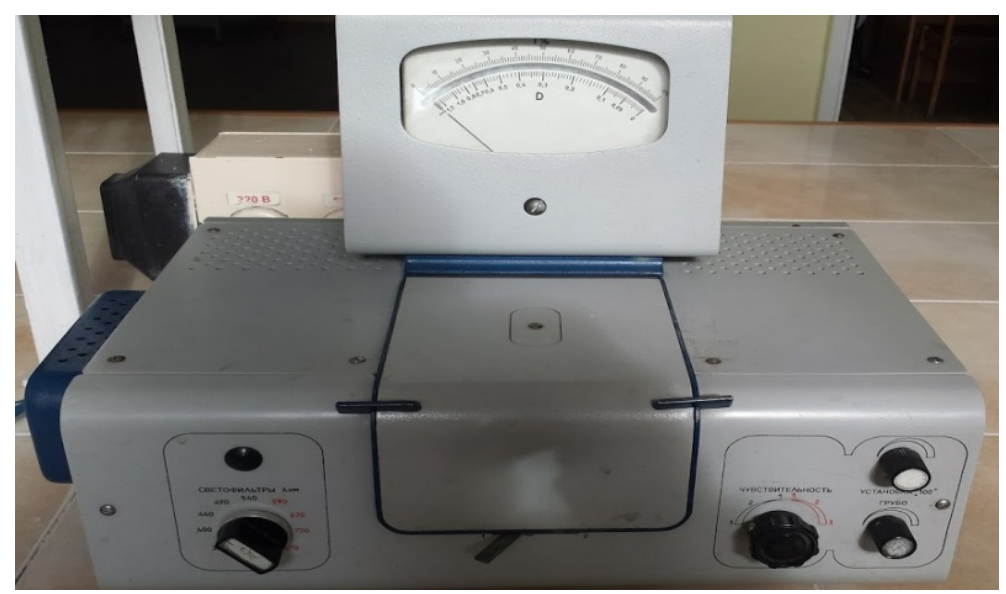

Fig. 1. Photocolorimeter CPC-2-CCC 4.2

The growth specific speed of microorganisms was determined by the formula:

$$
\mathrm{K}=\frac{1}{\mathrm{t}_{1}-\mathrm{t}_{2}} \cdot(\ln \mathrm{M} 2-\mathrm{M} 1)
$$

where $\mathrm{K}$ - growth specific speed; $\mathrm{t}$ - cultivation time, hours.; $\mathrm{M}$ - optic density, un. 
Generation duration was determined by the expression:

$$
\mathrm{Tp}=\frac{\lg 2}{\mathrm{~K}}
$$

where $\mathrm{Tp}$ - generation duration; $\mathrm{K}$ - growth specific weight.

The quantitative content of accumulated selenium was determined using the fluorimetric method using 2,3-diaminonaphthalene. The studied samples were demineralized at concentrated saline and nitrogen acids with further extraction by hexane. Water phases were poured off, organic ones were studied. The accounting of results was realized at presence and intensity of fluorescence of 4,5-benzopiazoselenol, extracted by hexane. Spectrums of luminescence were determined by a spectrometer SDL-1 (LOMO, Russia) with a mercurial lamp DSM (Lisma, Russia), light filter UVL-2 (Shott, Germany), at waves length 313 and 365nm (Fig. 2).

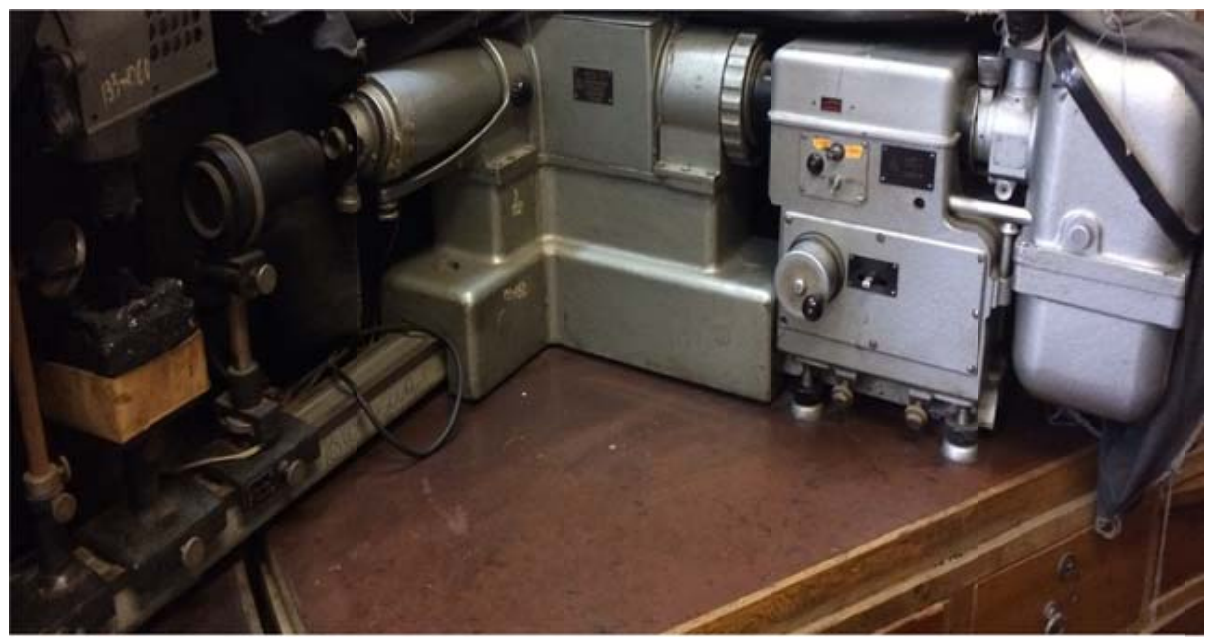

Fig. 2. Spectrometer SDL-1

Mathematical-statistical methods of the results processing were realized by conventional methods of mathematical statistics [11]. The value of the reliability index was found by Student table at reliable probability $\mathrm{P}=0,95$ and freedom degree $\mathrm{f}=\mathrm{n}-1$. The admissible value of relative mistake was the value that doesn't exceed $5 \%$.

\section{Experimental procedures}

Sodium selenite, introduced in the amount from 0,5 to $20 \mathrm{mcg} / \mathrm{cm}^{3}$ was chosen as a selenium source. Sodium selenite concentrations, higher than $20 \mathrm{mcg} / \mathrm{cm}^{3}$ negatively influenced the dynamic of accumulation of the studied microorganisms and process of their metabolism. The medium without sodium selenite was a control.

For creating the preparation, $0,1 \%$ sodium selenite solution in the amount $20 \mathrm{mcg} / \mathrm{cm}^{3}$ was added in the sterile MRS medium. Inoculate of the daily culture of lactobacteria was introduced in $5 \%$. Cultivation was realized during 24 hours at $37^{\circ} \mathrm{C}$. The received selenium-containing biomass of microorganisms was separated from cultivation using the centrifuging method (10 min, at 10000 turns/min). For removing non-assimilated selenium, the biomass was washed by sterile water. Then it was added with $37 \%$ saline acid and kept during 4 days. Saline acid was removed and the selenir um-containing biomass was kept at $-16{ }^{\circ} \mathrm{C}$, during 1 day. After that it was influenced by the microwave field. Using the vacuum-filter, nanostructures of selenium were separated from fragments of bacterial cells. The obtained preparation was liophilically dried. At first the product was tempered at the temperature $-30 \pm 1{ }^{\circ} \mathrm{C}$, during 12 hours. The product was stored in this state before loading in the sublimation apparatus. The initial process of drying was characterized by the decreasing pressure in the sublimation apparatus from the atmospheric one to $5^{\cdot} 10^{-1}$ or $5^{*} 10^{-2} \mathrm{~mm}$.m.c. In 1-1,5 hours after switching the vacuum-pump on, heating was switched on for intensification of 
the process of ice sublimation, to the temperature not higher than $-26 \pm 1{ }^{\circ} \mathrm{C}$. In 8 hours after the beginning of drying, the heating temperature was decreased to $37 \pm 1{ }^{\circ} \mathrm{C}$. The general duration of drying was 20-24 hours.

Nanostructural selenium is characterized by better biological accessibility for a macroorganism at the expanse of small sizes. This form of selenium can be used in the amount up to $250 \mathrm{mcg}$ a day. The obtained product contained near $180 \mathrm{mcg}$ of selenium in its composition.

\section{Results}

At the first stage the change of indices of the growth specific speed and generation duration was determined by obtained indices of optic density (Table 1).

\section{Table 1}

Change of indices of the growth specific speed and generation duration at cultivation of lactobacteria on MRS medium $(n=3, P \geq 0,95)$

\begin{tabular}{|c|c|c|c|c|c|c|c|c|}
\hline \multirow{3}{*}{$\begin{array}{c}\text { Amount of } \\
\text { sodium seleni- } \\
\mathrm{um}, \mathrm{mcg} / \mathrm{cm}^{3}\end{array}$} & \multicolumn{8}{|c|}{ Cultivation time, hours } \\
\hline & $0-5$ hours & $\begin{array}{c}0-10 \\
\text { hours }\end{array}$ & $0-15$ & $0-24$ & 0-5 hours & $\begin{array}{c}0-10 \\
\text { hours }\end{array}$ & $\begin{array}{c}0-15 \\
\text { hours }\end{array}$ & $\begin{array}{c}0-24 \\
\text { hours }\end{array}$ \\
\hline & \multicolumn{4}{|c|}{ Growth specific speed, hour-1 } & \multicolumn{4}{|c|}{ Generation duration, hour } \\
\hline 0 & 0,35 & 0,20 & 0,132 & 0,079 & 1,98 & 3,50 & 5,20 & 8,7 \\
\hline 0,5 & 0,35 & 0,20 & 0,132 & 0,079 & 1,98 & 3,50 & 5,20 & 8,7 \\
\hline 1 & 0,35 & 0,20 & 0,132 & 0,079 & 1,98 & 3,50 & 5,20 & 8,70 \\
\hline 2 & 0,36 & 0,20 & 0,130 & 0,079 & 1,92 & 3,50 & 5,30 & 8,70 \\
\hline 3 & 0,36 & 0,21 & 0,139 & 0,084 & 1,92 & 3,30 & 4,90 & 8,20 \\
\hline 5 & 0,35 & 0,18 & 0,119 & 0,072 & 1,98 & 3,85 & 5,70 & 9,50 \\
\hline 8 & 0,34 & 0,18 & 0,116 & 0,070 & 2,03 & 3,85 & 5,90 & 9,80 \\
\hline 10 & 0,33 & 0,17 & 0,110 & 0,067 & 2,10 & 4,0 & 6,20 & 10,2 \\
\hline 12 & 0,32 & 0,17 & 0,10 & 0,066 & 2,15 & 4,0 & 6,90 & 10,4 \\
\hline 14 & 0,32 & 0,16 & 0,10 & 0,066 & 2,15 & 4,30 & 6,90 & 10,4 \\
\hline 16 & 0,31 & 0,16 & 0,10 & 0,065 & 2,20 & 4,30 & 6,90 & 10,6 \\
\hline 18 & 0,31 & 0,16 & 0,10 & 0,064 & 2,20 & 4,30 & 6,90 & 10,7 \\
\hline 20 & 0,31 & 0,16 & 0,10 & 0,064 & 2,20 & 4,30 & 6,90 & 10,7 \\
\hline
\end{tabular}

It was revealed, that with increasing the sodium selenite concentration in the cultivation medium up to $8-20 \mathrm{mcg} / \mathrm{cm}^{3}$, there was observed the gradual delay of indices of the growth specific speed and increase of generation duration ones. Concentration of $\mathrm{Na}_{2} \mathrm{SeO}_{3}$ at the level $0,5-3 \mathrm{mcg} / \mathrm{cm}^{3}$ didn't cause the inhibiting influence on the dynamics of accumulation of the lactobacterial biomass.

The quantitative content of accumulated selenium by the studied probiotic microorganisms is presented on Fig. 3. 


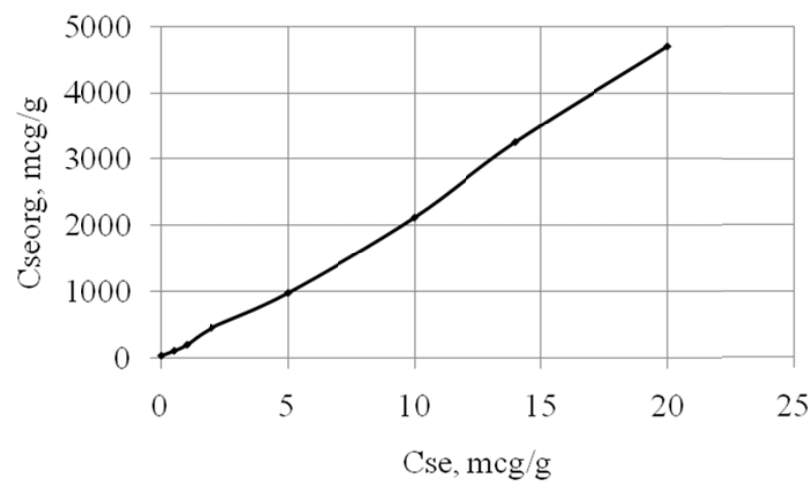

Fig. 3. Dependence between quantitative content of inorganic selenium in the cultivation medium and output of organic selenium

The initial factor that characterizes intensity of biomass saturation with selenium was indices of luminescence of the studied samples. It was established, that at the sodium selenite concentration $0,5 \mathrm{mcg} / \mathrm{cm}^{3}$ the content of organic selenium in $1 \mathrm{~g}$ of the biomass is $105 \mathrm{mcg}$. At the selenium source concentration in the cultivation medium $20 \mathrm{mcg} / \mathrm{cm}^{3}$, the selenium content is $4698 \mathrm{mcg} / \mathrm{g}$.

The direct dependence between intensity of accumulation of lactobacterial culture is explained by the absence of regulation mechanisms of selenium supply to cells in bacterial cells. The higher selenium concentration in the cultivation medium, the more amount of selenium is accumulated by microorganisms and biotransformed in the organic forms and nanostructures.

The process of lactobacteria cultivation on the cultivation medium with the high content of sodium selenite $\left(18-20 \mathrm{mcg} / \mathrm{cm}^{3}\right)$ was accompanied by the process of the change of metabolism of bacterial cells, connected with the active synthesis of selenium nanostructures. Selenium nanostructures were within bacterial cells, but at the active supply of inorganic selenium within bacterial cells, a part of synthesized nanostructures was extracted in the medium of microorganisms' cultivation that can be testified by pink coloration of the cultivation medium.

At the first stage of getting the preparation, based on selenium nanostructures, sodium selenite was introduced in the cultivation medium in the amount $20 \mathrm{mcg} / \mathrm{cm}^{3}$. But the important task in the process of getting selenium nanostructures was the choice of conditions for destruction of selenium-containing bacterial cells (Table 2).

Table 2

Influence of physical-chemical factors on destruction of bacterial cells

\begin{tabular}{ccccc}
\hline No. experiment & $\begin{array}{c}\text { Processing by } \\
\text { saline acid }\end{array}$ & Freezing & $\begin{array}{c}\text { Influence of micro- } \\
\text { wave field }\end{array}$ & Influence result \\
\hline 1 & - & - & + & + \\
2 & + & - & + & Cellular wall is not destructed \\
3 & - & + & + & Cellular wall is not destructed \\
4 & + & + & Cellular wall is destructed
\end{tabular}

It was established, that only combined influence of saline acid, freezing and microwave field causes destruction of cellular walls of the lactobacterial biomass.

The technological scheme of receiving "Nanoselenium" was developed, based on the obtained data (Fig. 4). 


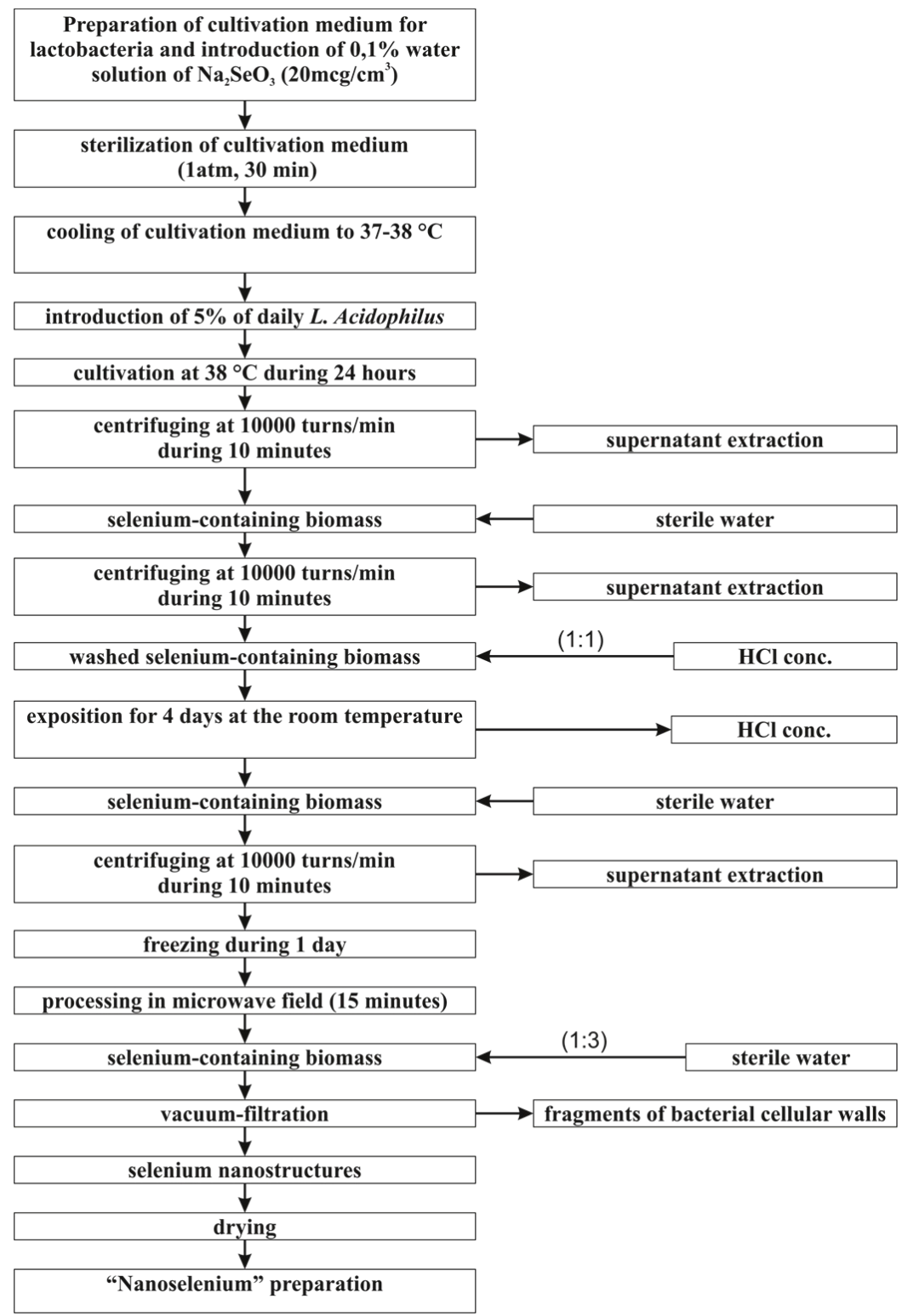

Fig. 4. Technological scheme of receiving "Nanoselenium" preparation

The presented scheme describes the technology of receiving "Nanoselenium" preparation. The characteristic of the received product is given in Table 3.

Table 3

Physical-chemical parameters of "Nanoselenium" preparation

\section{Parameter}

Look

Taste and smell

Color

Quantitative content of selenium, mcg/g

\section{Characteristic}

Powder with crystal mass

Specific

Pink-red

$180 \pm 1$

Using the fluorimetric method it was established, that the content of selenium in the preparation is $180 \pm 1 \mathrm{mcg} / \mathrm{g}$. 


\section{Discussion of research results}

Selenium nanostructures, obtained using Lactobacillus acidophilus culture 412/307, are the selenium-containing preparation of the new generation. Nanostructural selenium is safe for humans because of small sizes, but saves the whole spectrum of selenium positive effect. There are no analogues of such preparation in Ukraine.

The one of tasks of further studies is stabilization of received selenium, nanostructures, especially using water-soluble and non-toxic poly-N-vinylpyrrolidone. The urgent problem is the development of food products including selenium nanostructures.

\section{Conclusions}

1. The influence of the increasing sodium selenite concentrations $\left(0,5-20 \mathrm{mcg} / \mathrm{cm}^{3}\right)$ on the process of lactobacterial biomass accumulation was studied by indices of the change of the growth specific speed and generation duration. $\mathrm{Na}_{2} \mathrm{SeO}_{3}$ concentrations at the levels $0,5-5 \mathrm{mcg} / \mathrm{cm}^{3}$ didn't cause inhibition of lactobacterial biomass increment, such concentrations for bifidobacteria were $\left.0,5-5 \mathrm{mcg} / \mathrm{cm}^{3}\right)$.

2. There were chosen conditions that provide destruction of lactobacterial cells. Such as gradual influence of $37 \%$ saline acid (4 days), freezing ( 1 day at $\left.-16^{\circ} \mathrm{C}\right)$, and influence of the microwave field $\left(15\right.$ minutes at $\left.90^{\circ} \mathrm{C}\right)$.

3. The technological scheme of getting "Nanoselenium" preparation was developed, according to the obtained results.

4. The physical-chemical parameters of the obtained preparation were studied. It has the powder-like structure with pink-red color. The selenium content was $180 \pm 1 \mathrm{mcg}$.

\section{References}

[1] Shin, T. (2001). Selenium in the human organism. Journal of microbiolgy and biotechnology, $11,97-105$.

[2] Radhika, R. S., Gayathri, S. (2015). Extracellular biosynthesis of Selenium nanoparticles using some species of Lactobacillus. Indian Journal of Geo-Marine Sciences, 43 (5), 766-775.

[3] Oremland, R. S., Herbel, M. J., Blum, J. S., Langley, S., Beveridge, T. J., Ajayan, P. M. et. al. (2004). Structural and Spectral Features of Selenium Nanospheres Produced by Se-Respiring Bacteria. Applied and Environmental Microbiology, 70 (1), 52-60. doi: 10.1128/aem.70.1.52-60.2004

[4] Fesharaki, P. J., Nazari, P., Shakibaie, M., Rezaie, S., Banoee, M., Abdollahi, M., Shahverdi, A. R. (2010). Biosynthesis of selenium nanoparticles using Klebsiella pneumoniae and their recovery by a simple sterilization process. Brazilian Journal of Microbiology, 41 (2), 461-466. doi: 10.1590/s151783822010000200028

[5] Sasidharan, S., Balakrishnaraja, R. (2014). Comparison Studies on the Synthesis of Selenium Nanoparticles by Various Microorganisms. International Journal of Pure \& Applied Bioscience, 2 (1), 112-117.

[6] Prokisch, J. (2010). Process for Producing Elemental Selenium Nanospheres. United States, 634.

[7] Egorova, E. A. (2006). Poluchenie i eksperimental'naya otsenka novykh pishhevykh istochnikov organicheskikh form selena. Moscow, 121.

[8] Visha, P., Nanjappan, K., Selvaraj, P., Jayachandran, S., Elango, A., Kumaresan, G. (2015). Bioa synthesis and Structural Characteristics of Selenium Nanoparticles using Lactobacillus Acidophilus Bacteria by Wet Sterilization Process. International Journal of Advanced Veterinary Science and Technology, 4 (1), 178-183. doi: 10.23953/cloud.ijavst.183

[9] Nidhi, S. (2014). Biosynthesis of silver and selenium nanoparticles by Bacillus sp. JAPSK2 and evaluation of antimicrobial activity. Applied and environmental microbiology, 3, 135-141.

[10] Sonam, M. (2014). A superficial synthesis of selenium nanospheres using wet chemical approach. International Journal of Nanotechnology and Application, 3, 7-13.

[11] Pankov, A. R., Goryainova, E. R., Zhernosek, A. I. (2013). Statisticheskie metody obrabotki dannykh. Moscow, 212. 